\title{
ATRITOS CORPORAIS E LUTAS DE RESISTÊNCIA A PARTIR DO RELATO DE ÊXODO $^{1}$
}

\section{Bodily fights and resistance struggles according to the Exodus narratives}

\author{
Maria Liliane Silva de Oliveira ** \\ César Augusto Danelli Jr***
}

\section{Resumo:}

O presente texto nos faz perceber como se desenvolve o Êxodo no processo da caminhada feita pelo povo de ontem e os de hoje também, e que na inserção destes êxodos provocados pelo sistema de uma má organização e falta de compromisso com a vida vista como objeto se dá os atritos corporais. Na medida em que os acontecimentos afligem os corpos veremos acontecer às lutas de resistências do povo que almejam e buscam a libertação de seu corpo na tentativa de preservarem a sua identidade. A leitura nos apresenta a ideia de um corpo com capacidade de relacionalidade, que sente na pele a realidade do seu processo histórico, sabe o que é ser oprimido e se conhece capaz de construir sua própria história e, por isso, faz de tudo para manter a sua dignidade de ser humano, reconhece no decorrer do seu êxodo que nele está uma oportunidade de lutar pela libertação e esta sede de sair da opressão deve estar presente também na contemporaneidade.

Palavras-chave: Êxodo; Atritos Corporais; Lutas de Resistência pela Libertação.

\section{Abstract:}

This text makes us understand how the Exodus develops in the process of progress achieved by the people of yesterday and today, and that the inclusion of these exoduses caused by a bad organizational system and the lack of commitment to life, considers it as an object and thus causes a dissention regarding the body. The extent of events, that afflicts the bodies, is evident in the people's resistance who crave and seek the freedom of their body in an attempt to preserve their identities. The reading gives us the idea of a body with relational capacity, which witnesses the reality of its historical process, knows the significance of the oppression, and recognizes its ability to build its own history and, therefore, do everything possible to maintain the dignity of human beings and to understand that its departure deals with an opportunity to fight for the liberation, and this thirst to get out of oppression must also be present in the contemporary era.

Keywords: Exodus; Dissention Regarding the Body; Fight and Resistance for the Liberation.

1 Enviado em: 30.06.2017. Aceito em: 21.03.2020.

** Graduada em Teologia pelo Instituto Missioneiro de Teologia/URI, Campus de Santo Ângelo - RS. Pós - Graduação em Sagrada Escritura pelo Centro Universitário Claretiano de Batatais, SP. E-mail: oliveiralili.asf@gmail.com

*** Graduado em Direito. Mestre e Doutorando em Educação nas Ciências (UNIJUÍ). Professor da Faculdade de Balsas (Unibalsas). E-mail: cesardanelli@gmail.com

Protestantismo em Revista | São Leopoldo | v. 45, n. 02 | p. 148-157| Jul./dez. 2019 


\section{Introdução}

O presente texto nos proporcionará uma reflexão das lutas de resistência vivenciadas por um povo conforme a realidade do seu êxodo. É dentro deste contexto que os israelitas e as pessoas deste século despertam para a luta que visava a sua libertação. Com este tema teremos a oportunidade de fazer uma leitura de quatro tópicos. O primeiro nos fala das compreensões de êxodo que se constituíram pelos duros acontecimentos do quotidiano. Este ponto refere-se aos israelitas que chegaram no Egito. Os êxodos que vivenciaram são uma oportunidade de partida, saída e fuga da opressão causada por um sistema de governo comandada pela liderança de um Faraó.

O segundo tópico nos apresenta o êxodo e os sujeitos em luta pela libertação que ocorre de diferentes maneiras, assim como a exploração do corpo, as mortes e outras tentativas de domínio. Neste aspecto, o êxodo é vislumbrado por meio de uma percepção de vários sujeitos que ousam lutar pela libertação de seus corpos não apenas no sentido físico, mas, também na dimensão de tudo que integra o seu ser. Por isso, a intenção neste sentido, é apresentar o protagonismo de vários sujeitos para, em consequência, destacar a importância que cada pessoa pode ter enquanto sujeito da sua própria história mesmo diante das lutas acontecem de forma conjunta ou coletiva.

No terceiro tópico busca-se explicitar os atritos corporais e as lutas de resistência que sublinham como o corpo deve ou pode ser compreendido, pois muitas concepções nos levam a pensar em um corpo como um "casco" e nada mais. O intuito é perceber a dignidade do corpo que constitui o ser humano na sua expressão plural por meio de um sentido de totalidade. Perceberemos novas formas, ou seja, outros sentidos de lutas e de como resistir a dureza do êxodo.

O último tópico, o quarto, dá conta de como os corpos podem experimentar os sentidos da libertação na contemporaneidade. O objetivo é, pois, perceber os êxodos enfrentados neste novo século ao observar que a busca por libertação surge a partir da realidade de cada êxodo. Teremos a possibilidade de fazer uma reflexão dos acontecimentos acerca dos êxodos vivenciados e enfrentados na América Latina, e, de forma particular, no Brasil.

Nos quatro tópicos, se buscará evidenciar que a libertação é fomentada pela existência dos êxodos em que as pessoas buscam superar. Portanto, este artigo retrata a perspectiva dos atritos corporais, ou seja, os corpos na dimensão daquilo que os constitui frente aos desafios e lutas para resistir aos muitos êxodos que continuamente nos encontram no decorrer da sua história. $O$ foco maior é perceber como se dão as lutas de resistência dos corpos que almejam e buscam de sua libertação dentro dos êxodos impostos pelos sistemas vigentes. Busca-se assim, aprofundar uma leitura a partir dos seguintes autores: Carlos Rollsing, Gianfranco Ravasi, luri A.Reblin, José S. Croatto, Kathlen L. de Oliveira, Milton Schwantes, Michel de Foucault, Odéico T. Caten, Pedro Alonso P. Reyes, Tânia Maria V. Sampaio e de diversos textos bíblicos conforme a versão bíblica de Jerusalém.

\section{Compreensões de êxodo}

O êxodo é formado pelos acontecimentos vivenciados por um povo. Ele está presente nas diversas situações de torturas para com a vida. É algo que desafia para que pessoas busquem formas de subverter a lógica de opressão. No caso dos israelitas, segundo a afirmação de Sampaio, foi a fome que afligia os seus corpos e que estava inviabilizando suas vidas em suas casas. Tal fato, fez

Protestantismo em Revista | São Leopoldo | v. 45, n. 02 | p. 148-157| Jul./dez. 2019

Disponível em: <http://periodicos.est.edu.br/index.php/nepp> 
com que decidissem sair do seu lugar em direção ao Egito². Queremos a partir desta afirmação trazer presente os seguintes textos bíblicos:

Eis os nomes dos israelitas que entraram no Egito com Jacó; cada qual entrou com sua família: Rúben, Simão, Levi e Judá, Issacar, Zabulon e Benjamim, Dã e Neftali, Gad e Aser. Os descentes de Jacó eram, ao todo, setenta pessoas. José, porém, já estava no Egito. Depois José morreu, bem como todos os seus irmãos e toda aquela geração. Os israelitas foram fecundos e se multiplicaram; tornaram-se cada vez mais numerosos e poderosos, a tal ponto que o país ficou repleto deles. (Êx. 1,1-7)

Também,

Chegou ao poder sobre o Egito um novo rei, que não conhecia José. Ele disse à sua gente: Eis que o povo dos israelitas tornou-se numeroso e mais poderoso do que nós. Vinde, tomemos sábias medidas para impedir que ele cresça; pois do contrário, em caso de guerra, aumentará o número dos nossos adversários e combaterá contra nós, para depois sair do país. (Êx. 1,8-10)

Este jeito de pensar faz com que o Egito se torne a casa da escravidão. O Êxodo também significa partida. Ele é o segundo livro dos cincos livros que temos no conjunto do Pentateuco no Antigo Testamento. Nele se relata a dureza da vida vivenciada no Egito e as tentativas de libertação. Importa ressaltar que os israelitas no Egito estavam na condição de escravos sob o regime do sistema faraônico. Na opinião do biblista Milton Schwantes, é justamente no estado faraônico que se encontra a origem do êxodo. Nele, o governo obriga os trabalhadores a construir cidades como a de Ramessés, a capital do Egito. ${ }^{5}$

Percebemos assim, que o desejo por libertação é fruto da existência de um êxodo, pois é a partir dele que podemos falar de saídas/fugas/partidas para tentativas de libertação. O sentido da palavra êxodo nos faz perceber que não é fácil o caminho da libertação. Afinal, é difícil sermos dependentes, porque estamos sempre "trocando de patrão"6. Nesta troca, um sentido sempre acaba permanecendo - a submissão e a exploração. Portanto, em qualquer lugar em que alguém esteja vivenciando o êxodo, há também uma desafiadora e necessária luta para subverter a lógica da escravidão. Neste sentido, o Êxodo é um livro de grande valor na perspectiva da libertação. Para compreender melhor o que acontece no espaço do êxodo e do cativeiro, cabe observar, sobretudo, a realidade que perfaz vivência dos indivíduos que nela se encontram.

Toda forma de exploração, manipulação e controle do corpo tem a ver com a formação e constituição de um êxodo em seus meandros de criação. Corpo, neste sentido, não é somente algo que concerne aos sentidos físicos, mas, tudo aquilo que integra a dignidade do ser. A situação do êxodo se coloca diante de um sentido que é o da libertação. Assim, êxodo é o lugar em que se concebe a luta pela libertação, é a busca por sair da dominação e ser libertado.

A exploração no Egito também foi "exercida pelo poder político"7. Podemos constatar esta situação, por exemplo, no texto de (Êx. 1,11): "impuseram a Israel inspetores de obras para tornarIhe dura a vida com os trabalhos que Ihe exigiam" e ainda, conforme (Êx 1,13-14) "os egípcios obrigavam os israelitas ao trabalho, e tornavam-lhes amarga a vida com duros trabalhos [...]." Para

2 SAMPAIO, Tânia Maria V. Um Êxodo entre muitos outros êxodos - A beleza do transitório obscurecida pelo discurso do permanente: uma leitura de Êxodo 1 - 15. Revista de Interpretação Bíblica Latino-Americana/Ribla, Petrópolis: Vozes, 1996, p. 83. BÍBLIA DE JERUSALÉM, 2006, p.103.

BÍBLIA DE JERUSALÉM, 2006, p.103.

SCHWANTES, Milton. Breve história de Israel. São Leopoldo: Oikos, 2008, p. 14.

CROATTO, José S. Êxodo. ed. Paulinas, São Paulo, 1981. p. 38

CROATTO, 1981, p. 47.

Protestantismo em Revista | São Leopoldo | v. 45, n. 02 | p. 148-157| Jul./dez. 2019

Disponível em: <http://periodicos.est.edu.br/index.php/nepp> 
enfatizar um pouco mais acerca do contexto que se está falando, há que se destacar uma passagem do livro de Gênesis 15,13. "lahweh disse a Abrão: sabe, com certeza, que teus descendentes serão estrangeiros numa terra que não será a deles. Lá eles serão escravos, serão oprimidos durante quatrocentos anos". Nesta descrição é possível situar a época do evento com a informação de que tenha acontecido no século XIII a.C. Outro dado é que pode ter sido Ramsés II o faraó da opressão e Meneftá o faraó da fuga, segundo Ravasi ${ }^{8}$. Esta informação é importante para que possamos nos dar conta de que o faraó não foi apenas uma pessoa singular, mas, principalmente um sistema de governo.

\section{O êxodo e os sujeitos em luta pela libertação}

Se formos olhar para os textos bíblicos, o medo do Faraó começou quando este percebe que os israelitas estão fecundando e se multiplicando (Êx. 1,7). A partir disso é analisada a situação e a trama do êxodo: "Vinde, tomemos sábias medidas para impedir que ele cresça [...] impuseram a Israel inspetores de obras para tornar-lhe dura a vida com os trabalhos que the exigiam [...] Mas quanto mais os oprimiam, tanto mais se multiplicavam e cresciam" (Êx. 1,10; 11; 12).

O êxodo foi se dando de diversas formas: com duros trabalhos como nos relata o texto já mencionado acima; mortes de crianças: "Se for menino, matai-o" (v.16) e toda tentativa de dominação sobre o corpo. Dentro deste contexto surgem as lutas pela libertação. Cada sujeito tem sua forma de buscar o seu protagonismo. Importa ler o livro do Êxodo com um olhar descentralizado da pessoa de Moisés. Esta prerrogativa possibilita compreender melhor os sujeitos que participaram e lideraram a luta pela libertação.

Quando falamos do livro do Êxodo, em geral, centralizamos muito a atenção na pessoa de Moisés. Com isso, se reduz, sobremaneira, as diversas situações e formas de luta por libertação. Quase sempre se narra uma situação na qual o povo de Israel estava sendo oprimido e Deus enviou Moisés para libertá-los. Por isso, Moisés teria sido salvo. Atribui-se a Moisés a luta pela libertação. Tal postura facilita que este personagem seja colocado num lugar privilegiado de modo a não levar tanto em conta que outros sujeitos também participaram desta luta por libertação, provavelmente, até mesmo antes de Moisés!

Entre o povo que estava sendo oprimido e o Moisés "enviado" muitas lutas por libertação aconteceram. Se entendemos que no engajamento pela libertação há pessoas liderando uma luta por transformação, logo, será preciso ler o texto bíblico com um olhar atento para perceber que antes de Moisés já existiram pessoas engajadas neste processo de mudanças. Para melhor constatar quem foram os sujeitos que antecederam a Moisés, convém destacar algumas passagens bíblicas, como, por exemplo: "Mas quanto mais os oprimiam, tanto mais se multiplicava e cresciam" $(1,12)$. "As parteiras, porém, temeram a Deus [...], e deixaram os meninos viverem" $(1,17)$. "As mulheres dos hebreus...são cheias de vida e, antes que as parteiras cheguem, já deram à luz" $(1,19)$.

Certo homem da casa de Levi foi tomar por esposa uma descendente de Levi, a qual concebeu e deu à luz um filho. Vendo que era belo, escondeu-o por três meses. E como não pudesse mais escondê-lo, tomou um cesto de papiro, calafetou-o com betume e pez, colocou dentro a criança e a depôs nos juncos, à beira do Rio. De longe, uma irmã do menino observava o que the iria acontecer $(2,1-4) .^{9}$

8 RAVASI, Gianfranco. Êxodo. ed. Paulinas, São Paulo, 1985. p. 15.

9 BÍBLIA DE JERUSALÉM, 2006, p.104.

Protestantismo em Revista | São Leopoldo | v. 45, n. 02 | p. 148-157| Jul./dez. 2019

Disponível em: <http://periodicos.est.edu.br/index.php/nepp> 
"Eis que a filha do Faraó desceu para se lavar [...] Ela viu o cesto entre os juncos e mandou uma de suas servas apanhá-lo [...] Compadecida, disse: "É uma criança dos hebreus!" Então a sua irmã disse à filha do Faraó: "Queres que eu vá e te chame uma mulher dos hebreus que possa criar esta criança?" [...] Partiu, pois, a moça e chamou a mãe da criança [...] A mulher recebeu e a criou. Quando o menino cresceu, ela o entregou à filha do Faraó, a qual adotou e lhe pôs o nome de Moisés, dizendo: "Eu o tirei das águas" $(2,5-10) .{ }^{10}$

É importante nos darmos por conta que os meninos eram ameaçados de morte: "[...], observai as duas pedras. Se for menino, matai-o" $(1,16)$ diante disso, o Moisés era um menino ameaçado! Ele também de uma certa forma estava na inserção do êxodo: "Eu o tirei das águas" $(2,10)$, diante disso é possível notar que o seu êxodo não era da mão-de-obra escrava, mas de um corpo impossibilitado de viver para o além do respirar. É justo que reconheçamos a presença de mulheres que lutaram para a sua libertação usando suas estratégias para deixá-lo viver.

Diante destes textos queremos ressaltar o discernimento dos pais de Moisés que projetam uma saída para conservar a dignidade da vida. Isso também torna possível perceber que eles são sujeitos que vivem seu êxodo: a morte de um filho pode ser aquilo que enseja a busca pela libertação. Esta atitude pode nos falar de um novo projeto. A família de Moisés ensaiando formas de libertação. Digno de reconhecimento é a perspicácia da sua irmã que acompanha o percurso do objeto no qual se encontra o seu irmão. Nela também se pode contemplar uma capacidade de observar os acontecimentos. Percebemos no seu jeito de agir uma observação ativa. Ela age quando vai até a filha do Faraó postulando uma atitude de atenção e cuidado.

Queremos também apreciar as lutas pela libertação provindas das mãos das parteiras. As parteiras aqui não apressam os passos quando recebem a ordem do rei para não deixarem os meninos sobreviverem. A elas foi dado o poder de ter posse sobre a vida, mas elas utilizaram suas mãos com sabedoria. Elas entendem que suas mãos poderiam ser também instrumentos de libertação, invertendo o sentido de poder, que ao invés de dominar, deixa viver. "As mulheres dos hebreus não são como as egípcias. São cheias de vida e, antes que as parteiras cheguem já deram à luz" (v.19).

Até aqui fica claro que Moisés ainda não sabia o que era êxodo e o que vinha a ser uma luta por libertação. É por isso que é digno reconhecer as outras pessoas e os primeiros sujeitos a lutar por esta libertação para que não fiquem no anonimato tantas outras tentativas de lutas que também deixaram suas marcas nesta história de fugas/saídas/partidas. Não queremos aqui isolar Moisés no contexto da história, mas dizer que ele veio a se integrar nesta luta. Parece-nos importante que "O corpo humano é social: não apenas porque tem sexo e as capacidades de falar, de pensar e de se relacionar, mas porque precisa de outros corpos para sobreviver, sendo esta a interação na qual ele se percebe, conhece, descobre e cria sua identidade"11.

A identidade de Moisés surge de um povo. Sua identidade é de uma gestação, de uma mulher que deu a luz e que o amamentou. É encantadora a forma como as mulheres agem nesta luta por libertação. Elas não utilizaram varas, lutas corporais, mas, recorrem às armas das próprias mãos sensíveis que auxiliam a dar luz; o temor, ou seja, o amor e o respeito pela vida; o olhar que acompanha os movimentos da vida; as mãos que protegem das correntezas das águas e do seio que amamenta. Vida que sustenta com a entrega total de si.

10 BÍBLIA DE JERUSALÉM, 2006, p.104.

11 REBLIN, luri A. Para o alto e o avante: uma análise do universo criativo dos super-heróis. Porto Alegre: Asterisco, 2008. p. 44.

Protestantismo em Revista | São Leopoldo | v. 45, n. 02 | p. 148-157| Jul./dez. 2019

Disponível em: <http://periodicos.est.edu.br/index.php/nepp> 
Moisés percebeu uma sarça ardente, "olhou, e eis que a sarça ardia no fogo, e a sarça não se consumia" $(3,2)$, foi aí que ele se aproximou para ver "por que a sarça não se consome" (v.3) É aqui que inicia a sua participação na luta pela libertação na casa da escravidão. Antes dele agir é importante nos darmos conta que o próprio povo age em busca de sua libertação. Sim, o povo se expressa de tal forma a ponto de Deus se tornar conhecedor de seus êxodos/cativeiros:

"lahweh disse: "Eu vi, eu vi a miséria do meu povo que está no Egito. Ouvi seu grito por causa dos seus opressores; pois eu conheço as suas angústias. Por isso desci a fim de libertá-lo da mão dos egípcios[...]" (v.7-8), Deus também, manifesta sua ação quando o povo se expressa. Então, identificamos nesta leitura que Deus está com o povo na luta, mas o povo é que deve caminhar para escapar do êxodo/opressão com a sua manifestação de lamento.

A libertação da escravidão sob o Faraó é o acontecimento decisivo, é como a raiz viva da qual nasce recordação destacada da trama histórica de Israel; é sobretudo um acontecimento que pode renovar-se todas as vezes que Israel for escravo, nômade, peregrino e exilado, [...]. ${ }^{12}$

\section{Atritos corporais e as lutas de resistência}

Aqui trabalhamos com a ideia de corpo tentando perceber que o ser humano é uma unidade indivisível. Os atritos corporais se dão quando não se entende o corpo como uma totalidade. "Levando em conta essa afirmação, entendemos que expressões como matéria e espírito, corpo e alma, exterioridade e interioridade são formas que a linguagem tem para comunicar aspectos dessa unidade"13.

O povo que vivencia o êxodo não sofre apenas fisicamente, mas a dor atinge tudo o que integra a sua identidade como povo. Todos os corpos submissos eram e, de certa maneira, ainda hoje continuam sendo vistos como objetos. O nosso conceito de resistência aqui se refere a apreciar as formas de como o povo na tentativa de saídas para sobreviver o seu êxodo luta para resistir a opressão que tenta esmagar a vida. As resistências que temos aqui não se dão pelas armas de fogo e nem com passividade. As pessoas vão à luta como sujeitos de sua própria história.

As resistências acontecem pela continuidade das gestações de vida; pelas parteiras que resgatam a vida das crianças; pela sensibilidade das mulheres; quando as vozes não abafam sua dor, mas clamam pela libertação. Quando homens, mulheres e crianças estão na resistência pela dignidade de seu corpo. A leitura das lutas de resistência nos faz perceber um ser humano que se descobre como um ser pleno de dignidade. O Êxodo nos coloca diante de um exemplo de libertação que vai se concretizando e no qual podemos contemplar os aspectos históricos, políticos, sociais e religiosos.

\section{Os corpos experimentando libertação na contemporaneidade}

Queremos nos perguntar: “Onde e quando se dava aquela nova significação no Êxodo? [...] Não se trata de um fato isolado que aconteceu por volta do século XIII a.C., mas de um fato refletido, aprofundado, explorado pela fé e captado em todas as suas projeções"14. Por isso, é para nós hoje

12 RAVASI, 1985, p. 7;

13 REYES, Pedro Alonso Puentes. O corpo como parâmetro antropológico na bioética. Disponível em: www3.est.edu.br/biblioteca/btd/puentes_r_pa_td57htm. Acesso em: 19 Out. 2015, p. 14.

14 CROATTO, 1981, p. 40.

Protestantismo em Revista | São Leopoldo | v. 45, n. 02 | p. 148-157| Jul./dez. 2019

Disponível em: <http://periodicos.est.edu.br/index.php/nepp> 
uma mensagem embora lida em outros contextos e com outras participações de corpos. Podemos trazer aqui a realidade da América Latina, que começou o seu Êxodo quando aconteceu a "invasão colonialista, há mais de quinhentos anos"15. Sabemos que nas terras da América muitas "nações indígenas foram massacradas. Ouro e prata foram europeizados. As terras daqui foram aprisionadas pelos vencedores europeus. As pessoas foram aprisionadas"16 e muitos outros êxodos foram acontecendo - "Mordaças foram sendo impostas. As nações indígenas foram como que exiladas em sua própria terra". ${ }^{17}$

Croatto $^{18}$ nos conta que o êxodo não foi um episódio vivenciado apenas pelos hebreus, e com isto, ele nos alerta para o êxodo do presente em que estamos sendo escravizados economicamente, politicamente, socialmente e culturalmente. Precisamos nos dar conta de que a vida é pautada pela história e ela deve ser o motor que nos move. Fazer memória é não perder de vista os êxodos enfrentados e os muitos sonhos por libertação, os de ontem e os de hoje também. Por isso, é importante resgatar um pouco da história vivenciada no Brasil. A "poderosa" Europa nos séculos XV e XVI dominou "o mundo na época dos descobrimentos" ${ }^{19}$. Sabemos que o Brasil foi um país constituído a partir dos deslocamentos de pessoas. "O projeto europeu de conquista da América excluiu o elemento humano de seus empreendimentos, subjugando-o. Se o objetivo era rasgar a terra em busca de ouro e de outros metais, destruiu culturas e matou o corpo nativo" ${ }^{20}$. Com estes acontecimentos, não estamos mais perante um êxodo milenar, mas de êxodos cuja história está bem próxima de nós. E assim, o Egito e o êxodo vão se propagando em outros lugares e com outros rostos.

Os africanos, deportados para as Américas, foram subjugados à escravidão. Imigrantes foram feitos prestadores de serviços [...] Enfim, o capital apossou-se das grandes maiorias. Transformou-as em índios, negros, imigrantes e mestiços sem-terra [...] As pessoas foram ficando sem nada, a não ser com a escravidão ou o salário. Os povos latino-americanos foram transformados em exilados em seus próprios países. Aqui são habitantes, mas não cidadãos. ${ }^{21}$

O controle dos corpos de nossos semelhantes também são provocações de êxodos. "Há determinações que aprisionam sentidos" ${ }^{22}$, e um destes, neste caso, seria o da libertação. Os migrantes por aqui foram se formando como um povo e também passaram a se deslocar para outros lugares na tentativa de sobreviver sem serem tão explorados. Esta constatação deve nos fazer refletir para o fato de que juntamente com os índios, temos outros povos que também foram dominados. Por isso, o desafio é para que se tenha um olhar sensível, capaz de perceber que os povos trazidos de suas terras tiveram suas vidas exploradas longe de sua Pátria. Suas movimentações pelo território brasileiro não deixam de ser uma luta por libertação.

15 SCHWANTES, Milton. Sofrimento e esperança no exílio: história e teologia do povo de Deus no século VI a. C. São Paulo: Paulinas, 2007. p. 9.

16 SCHWANTES, 2007, p. 9.

17 SCHWANTES, 2007, p. 9

18 CROATTO, 1981, p. 41.

19 CATEN, Odécio Ten. Forma (s) de governo nas reduções guaranis. Sergio Antônio Fabris Editor. Porto Alegre, 2003. p. 17.

20 CATEN, 2003, p. 38.

21 SCHWANTES, 2007, p.9

22 OLIVEIRA, Kathlen Luana de. Por palavras e ações: há um mundo entre nós. Justiça, liberdade e comunhão: sentidos teológicos e políticos nos paradoxos da democracia em tempos de direitos humanos. Disponível em: <http://tede.est.edu.br/tede/tde_arquivos/1/TDE-2014-04-08T113613Z-477/Publico/oliveira_kl_td122.pdf>. Acesso em: 26 Mar. 2014, p. 109.

Protestantismo em Revista | São Leopoldo | v. 45, n. 02 | p. 148-157| Jul./dez. 2019 
Olhando para os migrantes, pode-se dizer que "a escravidão era a condição da pessoa que não pertencia a cidade" ${ }^{23}$, por isso, o desejo pela libertação vai consistir no "significado de movimento, a possibilidade de mover o corpo, de ir, sair de um lugar" 24 na tentativa de experimentar a libertação. Todos estes acontecimentos nos fazem observar que o êxodo perpassa a história de um povo. Bem por isso, é importante perceber que o Êxodo não foi apenas "um acontecimento [...] decisivo na história de uma pessoa ou de um povo, no momento em que aconteceu"25. O seu sentido está para muito além daquilo que aconteceu. O que está por trás da libertação e que representa algo peculiar é a "sua energia recriadora"26.

"Conforme as épocas, conforme o estado das lutas e a conjuntura prevalecem ora um ora outro aspecto" 27 . Muitas manifestações que temos presenciado ultimamente representam corpos conscientes de seus direitos e que se expressam em sua marcha por libertação. "Nossa experiência pessoal está cheia dessas manifestações - de - sentido, que só mais tarde, ou pouco a pouco, emergem de sua profundidade originalmente oculta" 28 . Pois, o Êxodo "nos faz recordar o que devemos ser e que ainda não somos"29: libertados de tudo que aprisiona, machuca e fere a dignidade humana. $O$ povo de hoje também sente fome. Fome de comida e de tudo que consiga dignificar a sua vida. E na tentativa de exercitar a sua plena cidadania que acontece a busca por justiça e equidade. O "Egito" de hoje está situado nas ruas, nas empresas, presídios, enfim, nos espaços em que a vida é explorada. As nossas ausências para com a dor do outro, a nossa insensibilidade e falta de capacidade para buscar um mundo e uma vida melhor, na maioria das vezes, faz com que não se busque um caminho de transformação em prol do bem comum. NO entanto, "não só há resistências e lutas. Há também avanços e conquistas [...] As lutas já se expressam em vitórias. Sim, os exílios não são eternos" ${ }^{30}$.

Os desterrados, porém, resistem, sonhando com o regresso ao seu Nordeste, aos seus respectivos países. Os indígenas resistem. As mulheres se organizam, resgatando seu corpo e o senso de sensibilidade. Os operários reivindicam. ${ }^{31}$

O momento do Êxodo é a oportunidade de nos lançarmos para os dias vindouros de nova vida e "A Bíblia nos anima a esta primavera. Fala-nos de exílios para nos encorajar à resistência, à organização e vitórias"32. Tudo isso são temas, que nos falam de tentativas de libertação, libertarse de tudo aquilo e daqueles que torna a vida uma jornada desafiadora para tanta gente. Sabemos que nestes "ensaios" muitos são as barreiras que fazem de tudo para manter o povo prisioneiro. Como pudemos ver anteriormente, alguns já acordaram para esta realidade e estão a lutar pelos seus direitos mesmo sabendo que "as constantes reportagens e os depoimentos dos representantes públicos tendem deslegitimar as inúmeras manifestações" ${ }^{33}$ de suas tentativas por uma vida digna.

23

24

25

26

27 FOUCAULT, 1981, p. 38.

Michel. Microfísica do Poder. Disponível em:< https://www.nodo50.org/insurgentes/biblioteca/A_Microfisica_do_Poder_-_Michel_Foulcault.pdf>. Acesso em: 22 Mar. 2014. p. 29.

28 CROATTO, 1981, p. 38.

29 CROATTO, 1981, p. 38.

30 SCHWANTES, 2007, p. 11.

31 SCHWANTES, 2007, p. 10.

32 SCHWANTES, 2007, p. 11.

33 OLIVEIRA, 2014, p. 63.

Protestantismo em Revista | São Leopoldo | v. 45, n. 02 | p. 148-157| Jul./dez. 2019

Disponível em: <http://periodicos.est.edu.br/index.php/nepp> 
Em tempo algum foi fácil para encontrar soluções em direção a uma vida melhor. Há muitos empecilhos.

O que estamos refletindo aqui nos coloca diante de um exílio que nos priva da liberdade de expressão, nos aprisiona a um poder que oprime. É a partir dos êxodos que somos aprisionados e compelidos a experimentar a libertação por meio da luta na qual nossos corpos são chamados a se colocarem em movimento. Infelizmente seguimos presenciando grandes índices de pessoas na busca por melhores condições de dignidade e cidadania. Não é coisa rara em nosso país, vermos a cada dia que passa, mais gente sendo alcançada pela miséria e a solidão ${ }^{34}$. 0 êxodo parece ser uma gestação de libertação lenta.

\section{Conclusão}

O desenvolvimento deste texto nos fez recordar o que nos diz Hannah Arendt: "a procura pela memória vem a ser ao mesmo tempo uma tentativa de fugir do que pode nos levar a dispersão" 35 . Portanto, o que aconteceu não pode jamais se tornar um passado apagado na nossa memória, mas um reflexo que nos possibilite enxergar, conhecer e permanecer em sintonia com a história não somente com a do passado, mas também com a do momento presente. Este texto nos possibilitou uma percepção de como se dá a constituição dos êxodos em nossas vidas, em épocas diferentes e vivenciadas por causas e pessoas diferentes. Em cada época conforme a realidade destes êxodos pôde-se notar que existe um desejo que é comum: a luta pela libertação. $O$ que refletimos aqui nos permitiu identificar quais são as causas que levam as pessoas a se depararem com o êxodo e, no decorrer da leitura tivemos o conhecimento de que qualquer sistema de governo mal investido desenvolve a criação de êxodo. A reflexão aqui descortinada possibilitou perceber que os acontecimentos ensejam lutas de resistência e libertação.

Esta leitura que nos apontou para o sonho de uma libertação que nos quer despertar para uma concepção de corpo enquanto integralidade no ser humano que tem a sua identidade, um corpo histórico e capaz de estabelecer relações consigo mesmo e com a sociedade. Somos, pois, desafiados e desafiadas a lutar como pessoas capazes de construir sua própria história e afirmar que não somos apenas um corpo físico. Trata-se de perceber as lutas de resistência enquanto meios para sair do cativeiro. Por fim, por meio deste texto também nós somos convidados e convidadas a sublinhar uma leitura da nossa história na perspectiva de perceber o nosso êxodo e de como enfrentá-lo diante das lutas presentes na nossa história do dia-a-dia.

\section{Referências}

ARENDT, Hannah. O conceito de amor em Santo Agostinho. Instituto Piaget. 2. ed. Lisboa, 1997. BÍBLIA, Tradução de Jerusalém. Antigo e Novo Testamento. Êxodo. São Paulo: Paulus, 2006. CATEN, Odécio Ten. Forma (s) de governo nas reduções guaranis. Sergio Antonio Fabris Editor. Porto Alegre, 2003.

CROATTO, José S. Êxodo. ed. Paulinas, São Paulo, 1981.

34 ROLLSING, Carlos. Inferno na terra prometida. Zero Hora, Porto Alegre, p.11 - 21, 7 Jun. 2015. p. 11.

35 ARENDT, Hannah. O conceito de amor em Santo Agostinho. Instituto Piaget. 2. ed. Lisboa, 1997, p. 68.

Protestantismo em Revista | São Leopoldo | v. 45, n. 02 | p. 148-157| Jul./dez. 2019

Disponível em: <http://periodicos.est.edu.br/index.php/nepp> 
FOUCAULT, Michel. Microfísica do Poder. Disponível em:< https://www.nodo50.org/insurgentes/biblioteca/A_Microfisica_do_Poder__Michel_Foulcault.pdf>. Acesso em: 22 Mar. 2014.

OLIVEIRA, Kathlen Luana de. Por palavras e ações: há um mundo entre nós. Justiça, liberdade e comunhão: sentidos teológicos e políticos nos paradoxos da democracia em tempos de direitos humanos. Disponível em: <http://tede.est.edu.br/tede/tde_arquivos/1/TDE-2014-04-08T113613Z477/Publico/oliveira_kl_td122.pdf>. Acesso em: 26 Mar. 2014.

RAVASI, Gianfranco. Êxodo. ed. Paulinas, São Paulo, 1985.

REBLIN, luri A. Para o alto e o avante: uma análise do universo criativo dos surper-heróis. Porto Alegre, RS: Asterisco, 2008.

ROLLSING, Carlos. Inferno na terra prometida. Zero Hora, Porto Alegre, p.11 - 21, 7 Jun. 2015.

REYES, Pedro Alonso Puentes. O corpo como parâmetro antropológico na bioética. Disponível em: <www3.est.edu.br/biblioteca/btd/puentes_r_pa_td57.htm>. Acesso em: 19 Out. 2015.

SAMPAIO, Tânia Maria V. Um Êxodo entre muitos outros êxodos - A beleza do transitório obscurecida pelo discurso do permanente: uma leitura de Êxodo 1 - 15. Revista de Interpretação Bíblica Latino-Americana/Ribla, Petrópolis: Vozes, p. 79-91, 1996.

SCHWANTES, Milton. Breve história de Israel. São Leopoldo: Oikos, 2008.

SCHWANTES, Milton. Sofrimento e esperança no exílio: história e teologia do povo de Deus no século VI a. C. São Paulo: Paulinas, 2007. 